\title{
$P$-wave crustal tomography of Greece with use of an accurate two-point ray tracer
}

\author{
George Drakatos, George Karantonis and George N. Stavrakakis \\ National Observatory of Athens, Institute of Geodynamics, Athens, Greece
}

\begin{abstract}
The three-dimensional velocity structure of the crust in the Aegean sea and the surrounding regions $\left(34.0^{\circ} \mathrm{N}\right.$ $42.0^{\circ} \mathrm{N}, 19.0^{\circ} \mathrm{E}-29.0^{\circ} \mathrm{E}$ ) is investigated by inversion of about 10000 residuals of arrival times of $P$-wave from local events. The resulting velocity structure shows strong horizontal variations due to the complicated crustal structure and the variations of crustal thickness. The northern part of the region generally shows high velocities. In the inner part of the volcanic arc (Southern Aegean area), relatively low velocities are observed, suggesting a large-scale absorption of seismic energy as confirmed by the low seismicity of the region. A low velocity zone was observed along the subduction zone of the region, up to a depth of $4 \mathrm{~km}$. The existence of such a zone could be due to granitic or other intrusions in the crust during the uplift of the region during Alpidic orogenesis.
\end{abstract}

Key words Greece - Aegean - tomography structure - velocity

\section{Introduction}

The Aegean and surrounding region is an area of extensive and complex deformations. The predominant tectonic features (fig. 1) are: i) the subduction of the African slab beneath the European plate along the Hellenic arc at a rate of about $1 \mathrm{~cm} / \mathrm{yr}^{-1}$ in an approximately N-S direction, and ii) the right-lateral motion of the North Anatolian fault and its continuation in the Northern Aegean sea (McKenzie, 1970, 1972, 1978; Papazachos and Comninakis, 1971; Dewey and Sengor, 1979; Hashida et al., 1988; Ligdas et al., 1990; Spakman et al., 1988, 1993).

Mailing address: Dr. George Drakatos, National Observatory of Athens, Institute of Geodynamics, P.O. Box 20048, 118-10 Athens, Greece; e-mail: g.drakat@egelados. gein.noa.gr
As expected, an area of extensive deformation reveals high seismic activity. The Hellenic arc shows remarkable features of island arc such as the existence of intermediate-depth earthquakes and volcanic activity.

There are several geophysical observations showing that this region is in an anomalous tectonic setting. A large positive anomaly of gravity is observed in the Central Aegean sea, while negative anomalies are observed in Turkey and on the Greek mainland (Makris, 1976, 1978; Chailas et al., 1992).

Geomagnetic anomalies have been observed along the volcanic arc and in the Northern Aegean trench (Makris, 1976). Heat flow data indicate a heat flow with a mean value of 2.1 HFU in the Northern and Central Aegean sea (Jongsma, 1974; Fytikas et al., 1985).

Crustal and upper mantle structure in the Eastern Mediterranean region has been studied by many investigators, who mainly focused on the lithosphere-asthenosphere system and on the upper mantle. The crustal thickness beneath 


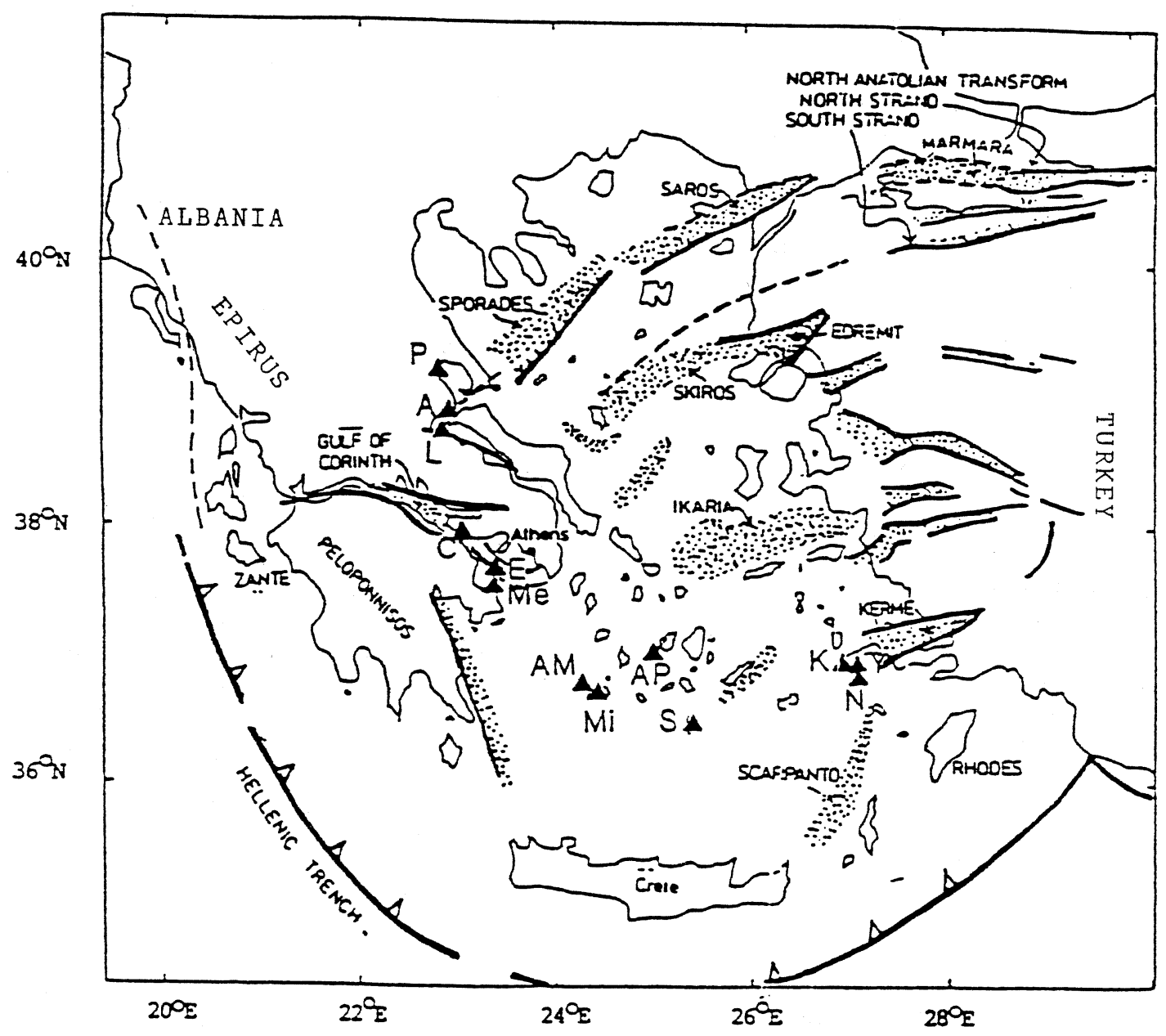

Fig. 1. Simplified summary of Greek tectonics, following Hashida et al. (1988). The heavy and broken lines indicate faults and poorly defined faults, respectively. The stippled areas show Neogene-Quaternary grabens. Solid triangles are volcanoes.

the Aegean sea is estimated, through the analysis of surface wave dispersion, to about $35 \mathrm{~km}$, under the Greek peninsula between $36 \mathrm{~km}$ to $42 \mathrm{~km}$ and under Macedonia and Southern Yugoslavia between $31 \mathrm{~km}$ and $47 \mathrm{~km}$ (Calcagnile et al., 1982). The crustal thickness has also been estimated by deep seismic soundings in the range of $46 \mathrm{~km}$ beneath Peloponnesos to 26 $\mathrm{km}$ under the Central Aegean region (Makris, 1978).
In the last decade, many investigators have studied the Eastern Mediterranean area using tomography techniques (Spakman, 1986, 1988; Spakman et al., 1988, 1993; Hashida et al., 1988; Ligdas et al., 1990; Wortel et al., 1990; Drakatos and Drakopoulos, 1991; De Jonge et al., 1993; Papazachos, 1994; Papazachos et al., 1995). In all the above mentioned studies the major features of the Aegean region have been obtained. 
The resolution and the reliability of the tomographic results strongly depend upon the degree of intersection of crossing rays. In the present study local events (reported in the ISC bulletin) in combination with a dense station network have been used to achieve the maximum degree of crossing rays and to thoroughly investigate the velocity anomalies in the crust of the region.

\section{Inversion method}

The inversion was performed using the progressive scheme proposed by Thurber (1983). Detailed description of the method and several assumptions used are given in Thurber (1983). Here, we will briefly review them, following Eberhart-Phillips (1986).

The method performs an iterative simultaneous inversion for $3 \mathrm{D}$ velocity structure and hypocenter parameters, using travel time residuals from local earthquakes. The velocity of the medium is parameterized by assigning velocity values at the intersections (grid points) of a nonuniform, three-dimensional grid. The spacing within the grid is selected by trying to have enough ray paths near each grid point so that its velocity may be well resolved. The velocity value at an arbitrary location within the model is given by the interpolation of the velocity values of the continuous nodes. As a ray tracing technique, the approximate ray tracing proposed by Thurber (1983) is used. This technique selects the ray paths as the arc with the fastest travel time out of a suite of circular arcs connecting the source and receiver. But this technique limits the application of the inversion when it is used for regional purposes and is not expected to perform well for station to source distances greater than $30 \mathrm{~km}$ (Thurber, 1983) or for areas in the order of $100 \mathrm{~km}$ (Eberhart-Phillips, 1986).

Therefore to decrease the travel time error resulting from the application of the approximate ray tracing and to limit the CPU time required in travel time computation, the twopoint 3D raytracing algorithm (Prothero et al., 1988 ) is used. This method relies on the direct minimization of the travel time by distorting the ray path from a starting path in a systematic way, until the smallest travel time value is found. Prothero et al. (1988) performed several tests and they proved that their algorithm has many advantages over other ray tracers.

\section{Data selection and model configuration}

The resolution and the reliability of the tomographic results strongly depend upon the degree of intersection of crossing rays. This presumes a dense station network with good distribution all over the investigated area. However, the particular geography of Greece with its very long and intricate coastlines and the numerous islands hampers this task. In order to overcome these difficulties, a «quality sensitive» spatial filtering technique was developed. The aim of this technique is to select from the total events located at the study area an evenly distributed data set that includes the larger (recorded at more stations), more recent (better quality and accuracy of seismic parameters) and deeper (longer rays, penetrating more at the study area) events. For this purpose the list of all the events located at the study area is sorted in decreasing order of number of phases, time and depth. The first event in the list is considered the centre of a cylinder with specific dimensions. The list of events is processed sequentially and all the events lying within this cylinder are removed. When this step is completed, the second event in the list is considered the centre of a new cylinder and the whole procedure is repeated to the last event. Therefore, in each cylindrical volume the largest, most recent and deepest event is selected. The r.m.s. time residual for this data selection is computed and the whole procedure can be repeated with new dimensions of the cylinder until a satisfactory low r.m.s. value and a suitable number of events is reached. It should be noted that the dimensions of the cylinder should always be less than the grid node spacing in order to secure that at least one event is located in each block determined by eight adjacent grid nodes. The same technique was also presented successfully by Louis et al. (1995) and by Alessandrini et al. (1995). 
The source of the data used is the catalogue of the ISC, for the time period 1964 to 1992. Originally, 16780 events were extracted independent of numbers of phases, depth and date. Then, in order to achieve an even distribution of events, the final data set was selected, following the procedure mentioned above and us- ing as radius of the cylindrical volume $50 \mathrm{~km}$ and height $20 \mathrm{~km}$.

Therefore, the final data set consists of 308 events (9949 first $P$-wave arrivals) located within the area between $34.0^{\circ} \mathrm{N}-42.0^{\circ} \mathrm{N}$, $19.0^{\circ} \mathrm{E}-29.0^{\circ} \mathrm{E}$ (fig 2). Each event was recorded by at least ten stations. The maximum

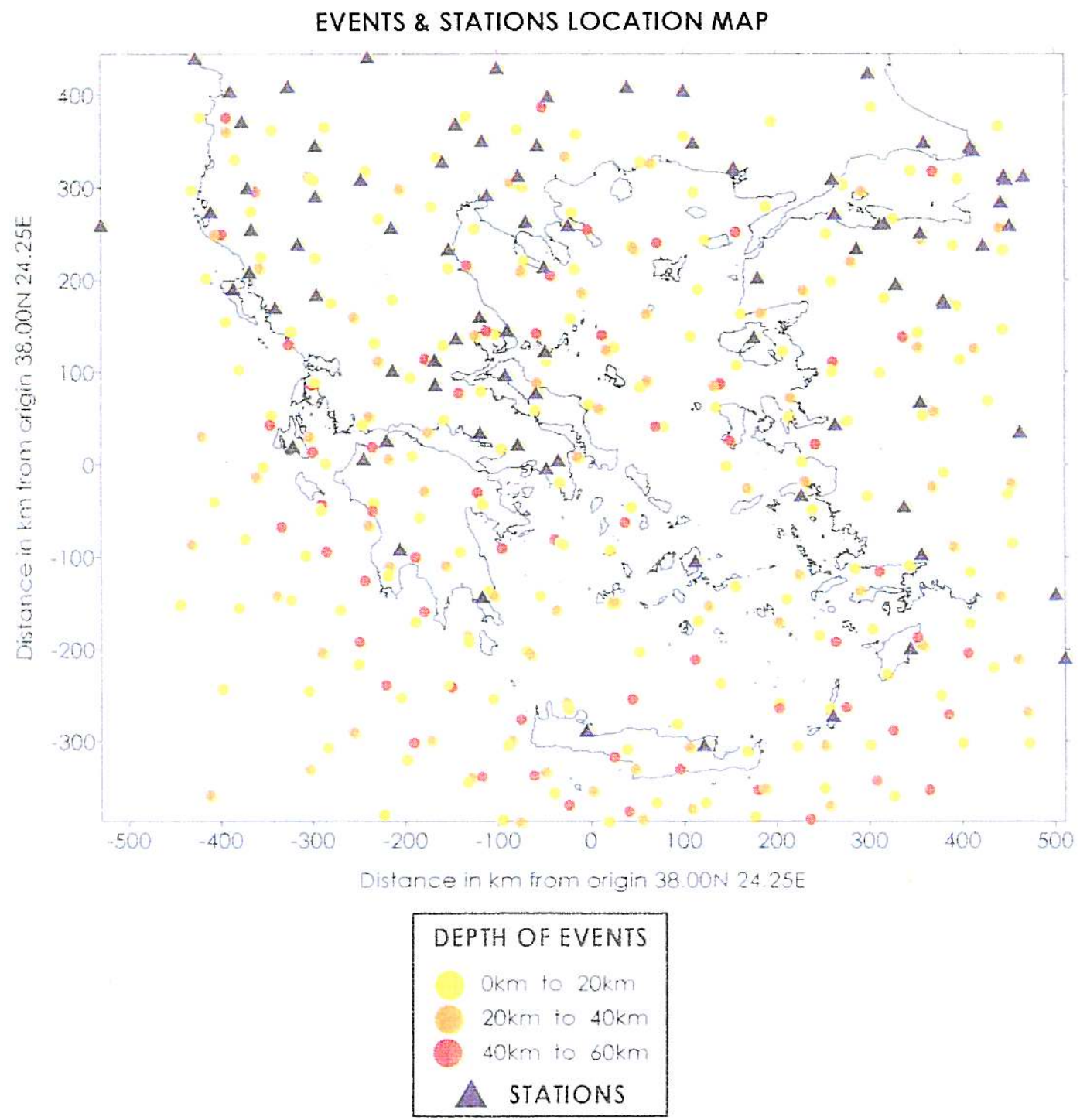

Fig. 2. Epicenter and station distributions are shown. 


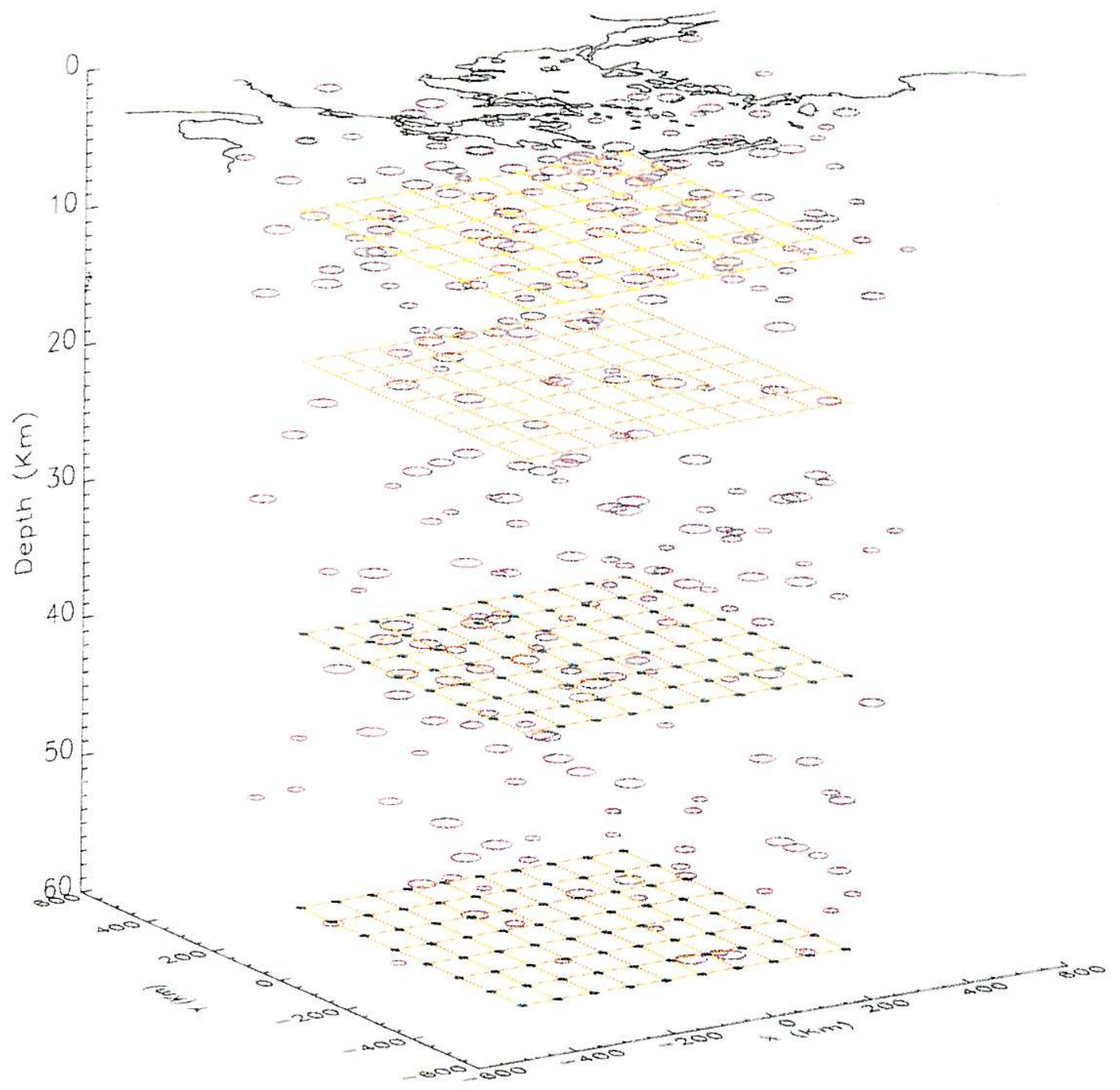

Fig. 3. 3D view of event distribution and of the grids of nodes.

depth of the events is $80 \mathrm{~km}$. The method used allows us to include in the data set events and stations which are not located inside the investigated area (tomography box). Therefore, there are several ray paths penetrating the peripheral nodes of the grid and increasing the resolution and the stability of the results. The 89 recording stations used in this study are located in the same area (fig. 2).
The $P$-wave velocity field is modeled through a $3 \mathrm{D}$ grid of nodes. Four horizontal grids were set at different depths. Each grid consisted of 80 nodes (10 along the latitude and 8 along the longitude) with a horizontal spacing of $70 \mathrm{~km}$ and $95 \mathrm{~km}$, respectively. Figure 3 shows the three-dimensional distribution of the events and the four grids of nodes. The starting $P$-wave velocity model is almost the 
same as that used in the Institute of Geodynamics of Athens for the determination of local events and is shown in table I, which summarizes the model configuration.

\section{Tomography results}

In order to check the stability of the solution and to detect slight variations of the velocity to the horizontal direction, after the first inversion the whole grid configuration was shifted to the $\mathrm{NE}$, by $40 \mathrm{~km}$. The inversion procedure was performed again.

So, in figs. 4a-d the results of the inversion are shown, in terms of velocity distribution to each node and after superposition of the two grids. Table II shows the resolution matrix of the results. As shown the values are very high, and not only in the «central» nodes. This is due to the very good epicenter distribution. As mentioned before, the method allows us to include in the analysis some events and stations out of the investigated area. Therefore, there are several rays crossing the peripheral nodes. But as shown comparing fig. 2 and figs. $4 a-d$, the peripheral nodes are not included in the results.

In the first grid (fig. 4a) of nodes (depth = $10 \mathrm{~km}$ ) low velocities are predominant. In particular, low velocities appear in the Southern Aegean region, in the Northwestern and Northeastern Peloponnesos region, along the upper crust of Western Turkey and in the western part of Epirus and Peloponnesos. Northern Greece shows high velocities $(6.1-6.5 \mathrm{~km} / \mathrm{s})$. Typical, upper crust velocities are also observed in the Epirus, Peloponnesos, Crete and Rhodes.

At a depth of $20 \mathrm{~km}$ (fig. 4b), along the subduction zone unexpected low velocities are predominant, as an extension of the low velocities which were determined in the first layer. This low velocity zone along the Hellenic trench regions appears to extend also in the third layer (fig. 4c) and seems to corresponds very well to African and Eurasian plate boundaries in the region.

At the same time, high velocities were detected «around» the Aegean sea region except for a low velocity spot at Ikaria region (fig. 4b).
Table I. Data and inversion parameters.

\begin{tabular}{ll}
\hline \hline Study region & $34.0^{\circ} \mathrm{N}-42.0^{\circ} \mathrm{N} 19.0^{\circ} \mathrm{E}-29.0^{\circ} \mathrm{E}$ \\
Structure model & $\begin{array}{l}4 \text { horizontal node layers in } 10, \\
20,40 \text { and } 60 \mathrm{~km}\end{array}$ \\
& $\begin{array}{l}10 \times 8 \times 4 \\
\text { Number of nodes NS Z }\end{array}$ \\
$\begin{array}{c}\text { Horizontal distance: } \\
\text { between nodes }\end{array}$ & $70 \mathrm{~km}-95 \mathrm{~km}$ \\
$\begin{array}{c}\text { Velocity model } \\
\begin{array}{c}\text { Number } \\
\text { of earthquakes }\end{array}\end{array}$ & $30.0,6.8,7.0,9.0 \mathrm{~km} / \mathrm{s}$ \\
$\begin{array}{c}\text { Number } \\
\text { of observations }\end{array}$ & 9949 \\
\hline
\end{tabular}

At a depth of $40 \mathrm{~km}$ (fig. 4c) high velocities are predominant in the investigated region. There is a gradual increase in the velocities from west to east and from north to south, which coincide very well with the boundaries of the subduction (Hellenic trench).

Finally, at a depth of $60 \mathrm{~km}$ (fig. 4d), typical upper mantle velocities are shown. Along the subduction zone, high velocity values are predominant as in the northwestern part of Greece. In this layer, the relatively low velocities in the Central Aegean region should be mentioned.

\section{Discussion and conclusions}

The first layer roughly corresponds to the sedimentary and the upper crustal layer. So the low velocity regions in Western Turkey (fig. 4a) nearly correspond to the distribution of Neogene-Quaternary grabens of Ikaria and Kerme (fig. 1). The influence of the Ikaria graben could also explain the low velocity spot $\left(\sim 6.2 \mathrm{~km} \mathrm{~s}^{-1}\right)$ in the second layer.

Beneath Northern Greece generally high velocities are predominant (fig. 5). The appearance of high velocities in the region of the North Aegean trench is a remarkable fact, as was also pointed out by Christodoulou and Hatzfeld (1988). They interpreted this fact as the result of the crust thinning, due to a large 

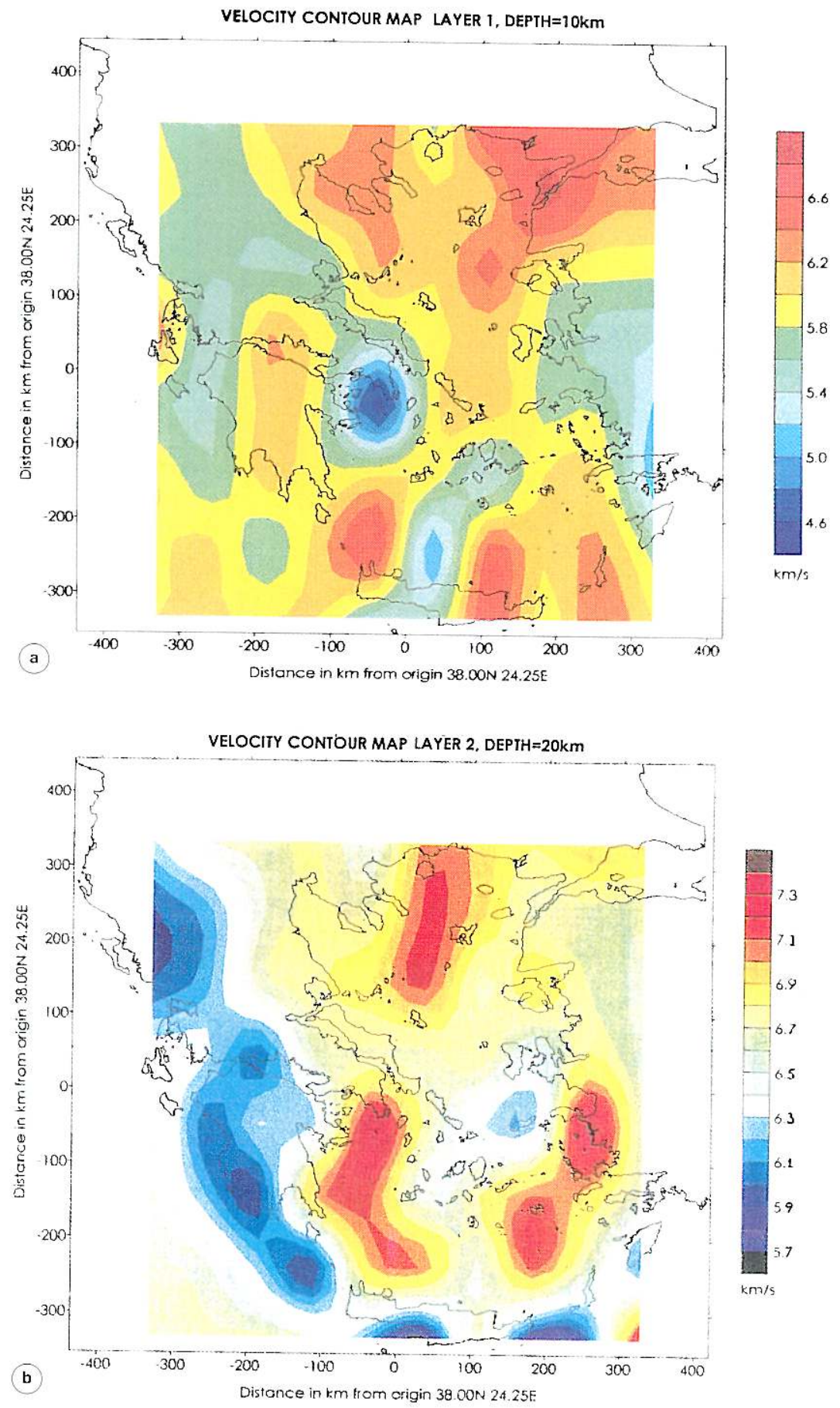

Fig. 4a,b. The results of the inversion are presented in terms of velocity variations for each grid of nodes. 

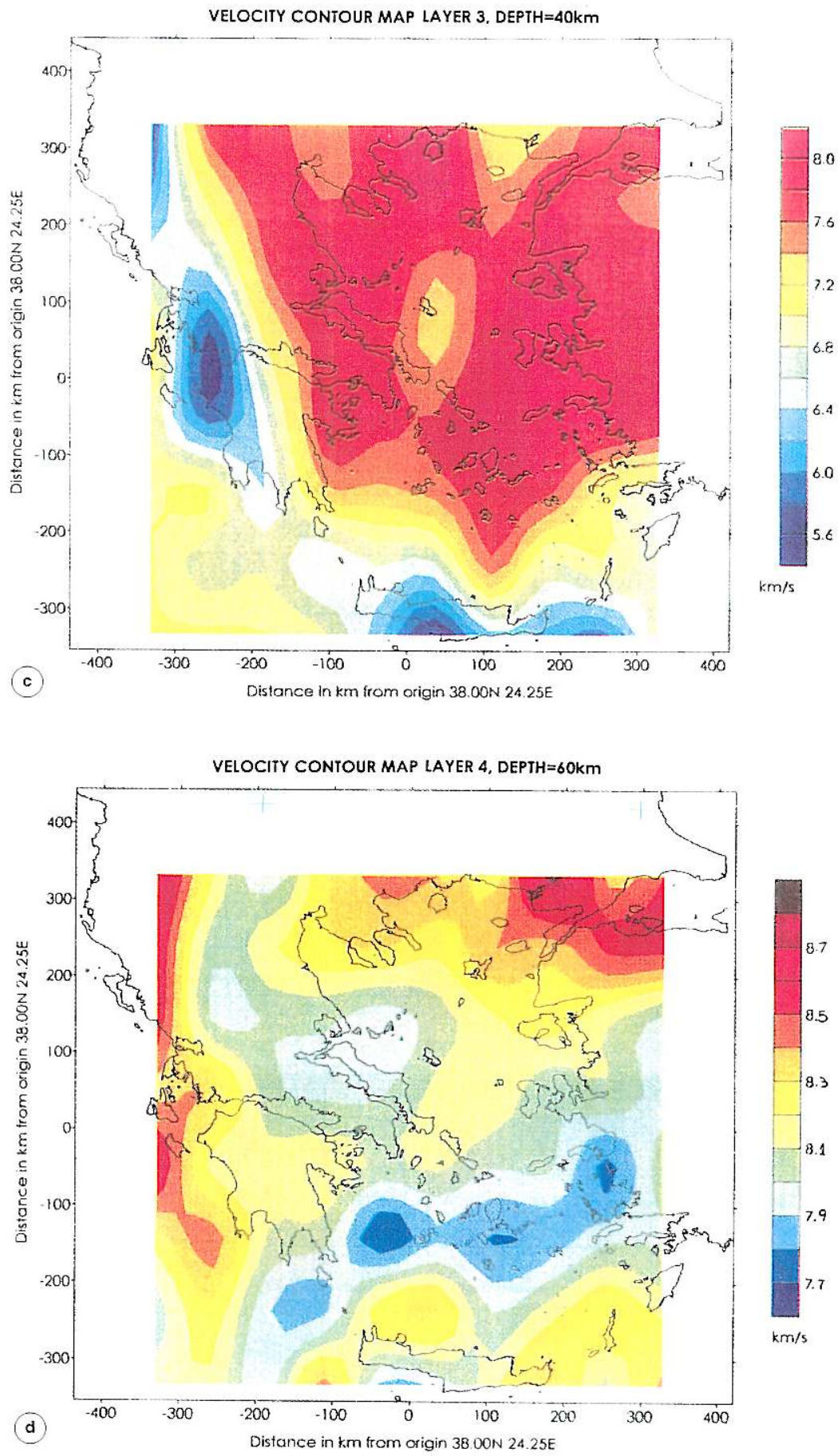

Fig. 4 c,d. The results of the inversion are presented in terms of velocity variations for each grid of nodes. 
Table II. The resolution matrix is shown.

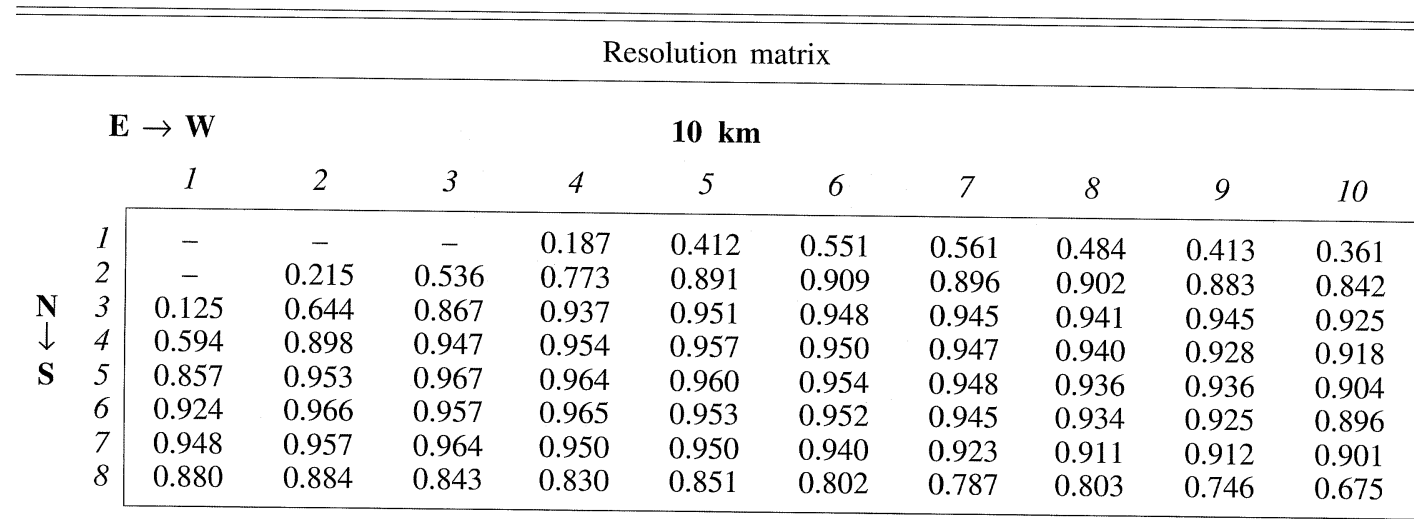

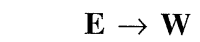

$20 \mathrm{~km}$

\begin{tabular}{|c|c|c|c|c|c|c|c|c|c|c|}
\hline & 1 & 2 & 3 & 4 & 5 & 6 & 7 & 8 & 9 & 10 \\
\hline 1 & - & - & - & 0.014 & 0.189 & 0.446 & 0.472 & 0.449 & 0.212 & 0.247 \\
\hline 2 & - & - & - & 0.324 & 0.581 & 0.751 & 0.668 & 0.572 & 0.649 & 0.509 \\
\hline $\mathbf{N}$ & - & 0.259 & 0.744 & 0.744 & 0.660 & 0.324 & 0.494 & 0.547 & 0.551 & 0.825 \\
\hline 4 & 0.626 & 0.884 & 0.889 & - & 0.782 & 0.060 & 0.526 & 0.425 & 0.522 & 0.671 \\
\hline 5 & 0.766 & 0.890 & 0.809 & 0.854 & 0.772 & 0.409 & 0.202 & 0.344 & 0.555 & 0.643 \\
\hline 6 & 0.874 & 0.896 & 0.855 & 0.831 & 0.840 & 0.618 & 0.715 & 0.747 & 0.389 & 0.643 \\
\hline 7 & 0.932 & 0.912 & 0.858 & 0.905 & 0.864 & 0.611 & 0.533 & 0.511 & 0.759 & 0.850 \\
\hline 8 & 0.939 & 0.847 & 0.848 & 0.886 & 0.781 & 0.595 & 0.636 & 0.501 & 0.586 & 0.751 \\
\hline
\end{tabular}

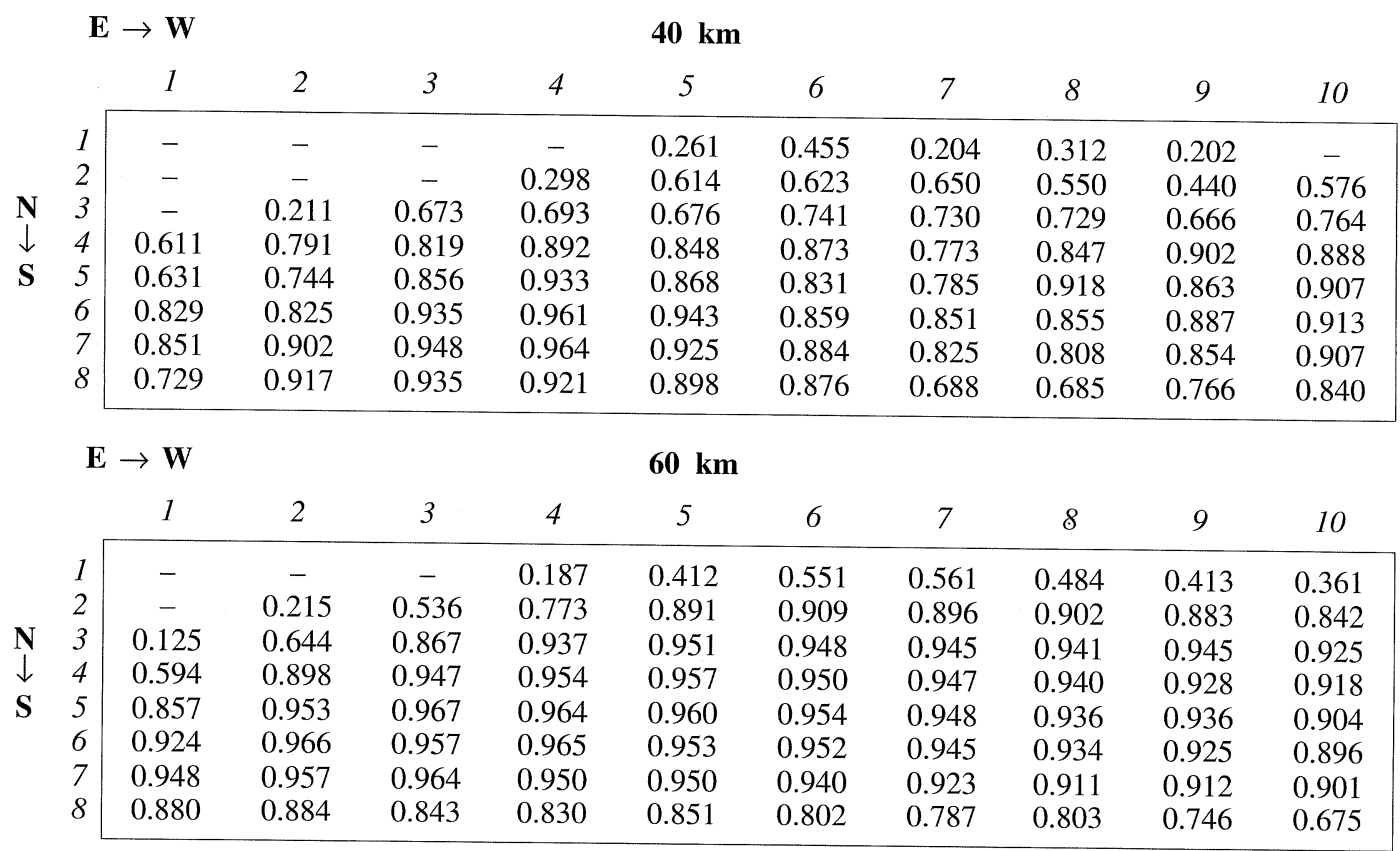




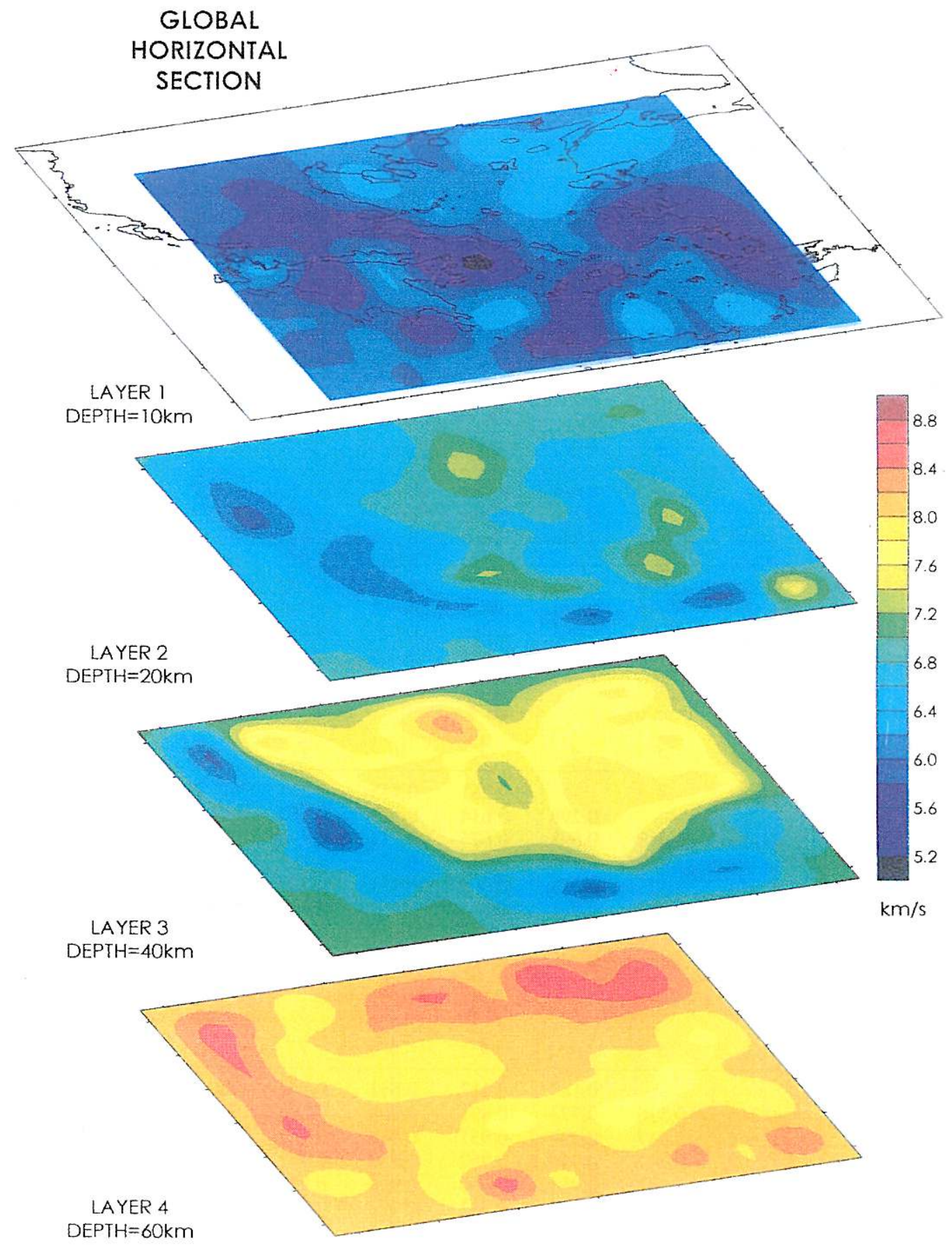

Fig. 5. 3D view of the velocity results is shown. 
scale extension which occurs in the region (Lyberis and Deschamps, 1982).

In the Southern Aegean region, relatively low velocities were observed in all layers (fig. 4a-d). This region coincides with the inner part of the volcanic arc (fig. 1). At a depth of $60 \mathrm{~km}$ (fig. 4d) the low velocity region in the Southern Aegean region is quite clear, suggesting a large-scale absorption of seismic energy in the region. The distribution of macroseismic intensities in the Central Aegean sea suggests a high attenuation in the inner part of the volcanic arc (Drakopoulos, 1978). Based on attenuation of $S$-waves, Delibasis (1982) supports the existence of magmatic material immediately beneath holes. A high viscosity zone exists in the area, which corresponds well to the aseismic region of the Aegean sea. The high attenuation zone exists beneath the isodepth of $100 \mathrm{~km}$, while beneath the volcanic arc this zone appears immediately beneath the Moho (Tassos, 1984). This is also supported by the low $Q$-value in the region, which is about 50-60 (Tassos, 1984; Hashida et al., 1988).

Beneath the Dinarides-Hellenides Mountain Chain, DHMC hereinafter according to $\mathrm{Pa}$ pazachos et al. (1995) (Albania, Peloponnesos, Crete, Rhodes, Southwestern Turkey), typical crustal velocities are determined up to a depth of $40 \mathrm{~km}$. The higher velocities in the inner part of these regions are due to the crust thinning (Makris, 1976).

At a depth of $40 \mathrm{~km}$ (fig. 4c) a sharp velocity contrast is observed. Along the DHMC the crust is about $35-40 \mathrm{~km}$ thick and the velocity values obtained correspond to typical crustal velocities. But in the Aegean region the crustal thickness is less than $30 \mathrm{~km}$, therefore the observed velocity values are higher (upper mantle velocities).

Finally, a low velocity zone was determined along the subduction zone, up to a depth of $40 \mathrm{~km}$. The existence of low velocities along a subduction zone is a surprising feature and the most important information of this study. According to Papazachos et al. (1995), the existence of such a velocity under this area (thicker crust-higher mountain chain) shows a possible connection with Alpidic orogenesis. Similar crustal low velocity layers at these depths have been reported for many other mountain chains (Swiss geotraverse, Buchi and Trumphy, 1976).

A connection seems to exist between the low velocity layer and areas of crustal thickening and vertical uplift like mountain chain. Landisman et al. (1971) and Muller (1977) suggest that the low velocity layer is due to granitic or other intrusions in the crust during this uplift.

Figure 5 shows a 3D view of velocity distribution, with the same color scale of the velocity for all layers. It can be shown that in the upper crust the velocity distribution «follows» the thickness of the crust. The low velocity zone along the Hellenic trench is also very well shown. This situation changes beneath the crust in the fourth layer, where typical higher velocity values are determined along the subduction zone.

This paper was an attempt to thoroughly investigate the velocity anomalies in the crust of a tectonically complicated area. The very high resolution values support a unique, stable and reliable velocity solution. A straight comparison between the results of this study and those of previous work is not possible, because of the different Earth structure sampling. In some of them the crust is treated as one layer and in others as a part of the first layer (Spakman, 1988; Spakman et al., 1988, 1993; Hashida et al., 1988; Drakatos 1989; Ligdas et al., 1990; Drakatos and Drakopoulos, 1991). However, the velocity anomalies for the first layer of their models roughly correspond to the present results. Moreover, the results of this study fit well with the gravity anomalies over Greece (Lagios et al., 1995).

\section{REFERENCES}

Alessandrini, B., L. Beranzoli, C. Falcone, F. Mele, G. Drakatos, G. Karantonis and G. Stavrakakis (1995): $P$-wave crustal velocity beneath the Central Mediterranean area from regional earthquake tomography, in 1995 AGU Fall Meeting, Book of Abstracts, p. F427.

BuCHI, U.P. and R. TRumPHY (1976): Bemerkungen zum geologischen Profillangs der Geotraverse Basel-Chiasso, Scheiz, Mineral. Petrogr. Mitt., 56, 589-603.

Calcagnile, G., F. D'Ingeo, P. Farrugia and G.F. PANZA (1982): The lithospere in the Central-Eastern Mediterranean area, Pure Appl. Geophys., 120, 389-406. 
Chailas, S., R.G. Hipkin and E. LAGIOs (1992): Isostatic studies in the Hellenides, in Paper presented at the 6th Congress of the Geological Society of Greece, Geol. Soc. of Greece, Athens, Greece, May 25-27.

Christodoulou, A. and D. HatzFeld (1988): Three-dimensional crustal and upper mantle structure beneath Chalkidiki (Northern Greece), Earth Planet. Sci. Lett., 88, 153-168.

Delibasis, N.D. (1982): Seismic wave attenuation in the upper mantle beneath the Aegean region, Pure Appl. Geophys., 120, 820-839.

De Jonge, M.R., M.J.R. Wortel and W. SPAKMAN (1993): From tectonic reconstruction to upper mantle model: an application to the Alpine-Mediterranean region, Tectonophysics, 223, 53-65.

DEWEY, J.F. and A.M.C. SENGOR (1979): Aegean and surrounding region: complex multiplate and continuum tectonics in a convergent zone, Bull. Geol. Soc. Am., 90, 84-92.

Drakatos, G. (1989): Seismic tomography - Determination of high and low velocity zones beneath Greece and surrounding regions, Ph.D. Thesis, University of Athens, Athens, Greece, pp. 144.

Drakatos, G. and J. Drakopoulos (1991): 3D velocity structure beneath the crust and upper mantle of the Aegean sea region, Pure Appl. Geophys., 135, 401-420.

DRAKOPOUlos, J. (1978): Attenuation of intensities with distance for shallow earthquakes in the area of Greece, Boll. Geof. Teor. Appl., 20, 114-130.

EBERHART-PHILliPS, D. (1986): Three-dimensional velocity structure in Northern California coast ranges from inversion of local earthquake arrival times, Bull. Seism. Soc. Am., 76 (4), 1025-1052.

Fytikas, M., F. InNocenti, P. Manetti, R., Mazzuoli, A. PeCCERILlo and L. Villari (1985): Tertiary to Quaternary evolution of the volcanism in the Aegean region, in The Geological Evolution of the Eastern Mediterranean, edited by J.E. DIXON and A.H.F. Robertson, Geol. Soc. Spec. Publ., London, 17, 687-699.

Hashida, T., G. Stavrakakis and K. Shimazaki (1988): Three-dimensional seismic attenuation structure beneath the Aegean region and its tectonic implication, Tectonophysics, 145, 43-54.

Jongsma, D. (1974): Heat flow in the Aegean sea, Geophys. J. R. Astron. Soc., 37, 337-346.

LAGIOS, E., S. ChaIlas and R.G. HiPKIN (1995): Gravity and isostatic anomaly maps of Greece, EOS (Trans. Am. Geophys. Un.), 76, 851-860.

Landisman, M., S. Mueller and B.J. Mitchel (1971): Review of evidence for velocity inversions in the continental crust, in The Structure and Physical Properties of the Earth's Crust, «Geophys. Monogr. Ser.», edited by J.G. HEACOCK, 14, 11-34 (AGU, Washington, D.C.).

LIGDAS, C.N., I.G. MAIN and R.D. ADAMS (1990): 3D structure of the lithosphere in the Aegean sea region, Geophys. J. Int., 102, 219-229.

Louis, F.I., G.A. Karantonis, K.C. Makropoulos and D. HATZFELD (1995): Tomographic images of $P$-wave velocity distribution at the Central and Southern Aegean sea area, Greece, in 4th Congress International Geophysics Society of Brasil and 1st Conference of the
Latino-American Union of Geophysics, 20-24 August 1995, Rio de Janeiro, Brasil, Expanded Abstracts, vol. II, 1083-1086.

LyBERIS, N. and A. Deschamps (1982): Sismo-tectonique du Foss Nord Egeen: Relations avec la faille NordAnatolienne, C.R. Acad. Sci. Paris, 295, 625-628.

MAKRIS, J. (1976): A dynamic model of the Hellenic arc deduced from geophysical data, Tectonophysics, $\mathbf{3 6}$ 339-346.

MAKRIS, J. (1978): The crust and upper mantle of the Aegean region from deep seismic soundings, Tectonophysics, 46, 269-284.

MCKenzIE, D.P. (1970): The plate tectonics of the Mediterranean region, Nature, 226, 239-243.

MCKENZIE, D.P. (1972): Activity tectonics of the Mediterranean region, Geophys. J. R. Astron. Soc., 30, 109-185.

McKenzIE, D.P. (1978): Active tectonics of the AlpineHimalayan belt: the Aegean sea and surrounding regions, Geophys. J. R. Astron. Soc., 55, 217-254.

Mueller, S. (1977): A new model of the continental crust, in The Earth's Crust: its Nature and Physical properties, «Geophys. Monogr. Ser.», edited by J.G. HEACOCK, 20, 289-317 (AGU, Washington, D.C.).

PAPAzACHOS, B.C. and P.E. CoMnINAKIS (1971): Geophysical and tectonic features of the Aegean arc, J. Geophys. Res., 76, 8517-8533.

PAPAZACHOS, C.B. (1994): Structure of the crust and upper mantle in SE Europe by inversion of seismic and gravimetric data, Ph.D. Thesis, University of Thessaloniki, Thessaloniki, Greece, pp. 208 (in Greek).

Papazachos, C.B., P.M. Hatzidimitriou, D.G. PANAGIOTOPOULOS and G.N. TsOKAS (1995): Tomography of the crust and upper mantle in Southeast Europe, J. Geophys. Res., 100 (B7), 12405-12422.

Prothero, W.A., W.J. TAYlor and J.A. EicKemeyer (1988): A fast two-point three-dimensional ray-tracing algorithm using a simple step search method, Bull. Seism. Soc. Am., 78, 1190-1198.

SPAKMAN, W. (1986): Subduction beneath Eurasia in connection with the Mesozoic Tethys, Geol. Mijnbow., 65, 145-153.

SPAKMAN, W. (1988): Upper mantle delay time tomography with an application to the collision zone of the Eurasian, African and Arabian plates, Ph.D. Thesis, University of Utrecht, Utrecht, Netherlands, pp. 200.

SPAKMAN, W., M.J.R. WORTEL and N.J. VlaAR (1988): The Hellenic subduction zone: a tomographic image and its dynamic implications, Geophys. Res. Lett., 15, 60-63.

SPAKMAN, W., S. VAN DER LEE and R.D. VAN DER HILST (1993): Travel-time tomography of the EuropeanMediterranean mantle down to $1400 \mathrm{~km}$, Phys. Earth Planet. Inter., 79, 3-74.

TAssos, T.S. (1984): Static and dynamic properties of upper mantle in Southern Aegean sea, Ph.D. Thesis, University of Thessaloniki, Thessaloniki, Greece (in Greek).

THuRBER, C.H. (1983): Earthquake locations and three-dimensional structure in the Coyote Lake area, Central California, J. Geophys. Res., 88, 8226-8236.

Wortel, M.J.R., S.B.D. Goes and W. Spakman (1990): Structure and seismicity of the Aegean subduction zone, Terra Nova, 2, 554-562. 